\title{
FROM REAL TO... "REAL". A REVIEW OF GEOMATIC AND RAPID PROTOTYPING TECHNIQUES FOR SOLID MODELLING IN CULTURAL HERITAGE FIELD.
}

\author{
G. Tucci, V. Bonora
}

GECO - Lab. of Geomatic and Communication, DiCR, Univ. of Florence - (grazia.tucci@unifi.it, valentina.bonora@archimetro.it)

KEY WORDS: Rapid prototyping, Additive Manufacturing, Architectural Model, Solid Model, 3D scanner

\begin{abstract}
:
The documentation and 3D modelling of Cultural Heritage are now mainly based on digital techniques to produce complete, detailed and photorealistic three-dimensional surveys. The integration of various technologies and sensors is the best solution to obtain results with these characteristics. According to the reproduction scale, you need to change the characteristics of the instruments used during acquisition.
\end{abstract}

Reduced or real scale solid models are an effective support for projects involving communication and divulgation: they can be understood without the intermediation of data processing systems, therefore increasing the potential users.

Additive Manufacturing (AM) is an expression indicative of technologies used to fabricate physical objects directly from CAD data sources; they are also called three-dimensional printing, solid freeform fabrication or layered manufacturing. The paper analyzes only factors related to the processing that involves the superficial aspect of the solid model; some important aspects useful in other applications, e.g. mechanical behaviour of the used material or the method to realize the internal structure or possible supports of the model, are neglected.

\section{INDTRODUCTION}

The documentation and 3D modelling of Cultural Heritage are now mainly based on digital techniques to produce complete, detailed and photorealistic three-dimensional surveys. The integration of various technologies and sensors is the best solution to obtain results with these characteristics.

According to the reproduction scale, you need to change the characteristics of the instruments used during acquisition.

Models can be divided into "real scale and real aspect models" (models of objects, statues, etc.) and "reduced scale models" (models of buildings, archaeological excavations, etc.).

In both cases the quantity of the 3D data available and their level of detail provide solid reproductions using rapid prototyping techniques.

Reduced or real scale solid models are an effective support for projects involving communication and divulgation: they can be understood without the intermediation of data processing systems, therefore increasing the potential users.

\section{Full scale models}

Some objects can be reproduced in full scale, such as for example archaeological finds, sculptures, decorative elements and so on. Generally, acquisitions are carried out with triangulation or pattern projection systems, which have a limited operating range and provide an accuracy of $0.1 \mathrm{~mm}$.

Scanning's intent is to document the whole surface; the instrument doesn't detect certain parts, though, due to its operating limitations: to be able to detect a point, it should be in sight from both the projection system and the lens.

\section{Reduced scale models}

In architectural scale, reproduction is carried out on a reduced scale and acquisition can be limited to the portions we are interested in and/or integrated during the following stages. Generally, the instruments used include distance scanners, which provide centimetric accuracy. In this case the lack of data can be due also to the presence of furniture or other encumbrance on the scene.

The growing rapidity of the acquisition phase - enabled by the technological evolution of scanners, which are quicker and quicker, and by the spreading of image based techniques allows increasing documentation, as well as what is immediately necessary. This way we create a database of metric information from which we can draw all the necessary data for graphic representation. A point model as complete as possible is useful to meet documentation needs that have not been planned at the very beginning, saving a huge amount of money. 


\section{3D SCANNING SYSTEMS}

It is not possible to provide here an exhaustive overview of the scanning systems available to document objects with different size. We can now replace the traditional distinction between "terrestrial LIDAR" and "triangulation" systems with more complex classifications. For example, even among terrestrial scanners we can find static and dynamic systems (e.g. HandyScan and Artec MH are "handheld" systems).

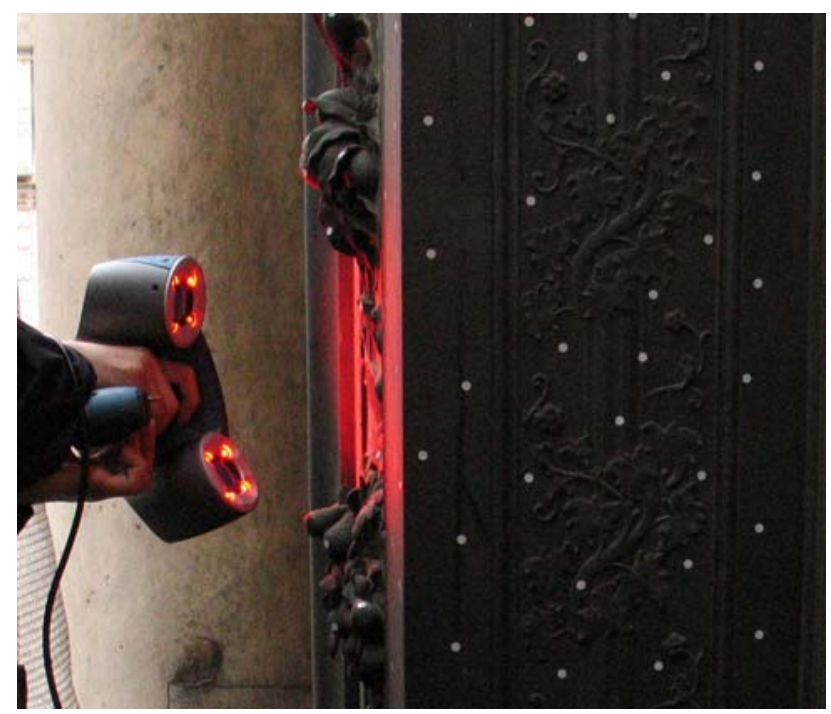

Figure 1. Handyscan system (Creaform); the target are used for self-positioninig, without any external tracking device

The systems based on the projection of lighting references (spot, strips, pattern) are manifold and their precision varies from 1 millimetre to $0.1 \mathrm{~mm}$. As far as costs are concerned, they are clearly influenced by the quality of the hardware, which in triangulation systems is always linked to specific software for data processing. The border line between scanning systems and photogrammetric systems is therefore thinner and thinner because of the consolidated diffusion of algorithms for image correlation.

The renewed interest in range cameras suggests including these instruments too in "scanning systems", on the basis of the data they produce: models of points that sample the surface on sight (from the instrument) with higher intensity compared to the size of the object. Despite the above-mentioned technological differences and the fact that almost ten years have passed, the definition of scanning systems proposed by Böhler and Marbs (Böhler and Marbs, 2002) at the very beginning is still valid: "any device that collects 3D co-ordinates of a given region of an object's surface automatically and in a systematic pattern at a high rate (hundreds or thousands of points per second) achieving the results (e.g. three-dimensional co-ordinates) in (near) real time".

If we group the scanning systems based on the principle of measurement we can notice:

- terrestrial LIDAR scanners,

- Triangulation scanners,

- Handheld scanners,

- T-Scan.

The data acquired with the first two types of instruments always need alignment after scanning. In the first case this process can be speeded up by using targets that are labelled homogeneously for every scanning (in order to enable their automatic recognition as homologous points), while in the second it is possible to use a rotating support to survey round objects. Knowing the rotation performed by the support between one scanning and the other allows setting the roto-traslation parameters (at least a first approximation) for alignment.

With the last two instruments, at the end of the scanning phase, the acquisition device immediately give a complete and referenced unstructured model of points of the object. The alignment of multiple range maps is not necessary, neither is the elaboration aimed at reducing the oversampling effect produced by their overlapping.

We tested T-Scan, together with Laser tracker system, to survey a statue (see Figure 2). The mesh model has been directly calculated; the mesh quality is very good: triangular faces are quite regular, with few manifold triangles and overlapping ones, and only some small holes in regular surfaces (probably where T-Scan movement was a little too speedy). In the more articulated area there have been some isolated surface patches. These problems, which would prevent a rapid prototyping machine from successfully generating a useful solid model, have been quickly fixed. More demanding has been the reconstruction of the holes where the shape of the original model was so complex that acquiring data was impossible, as in some curls.

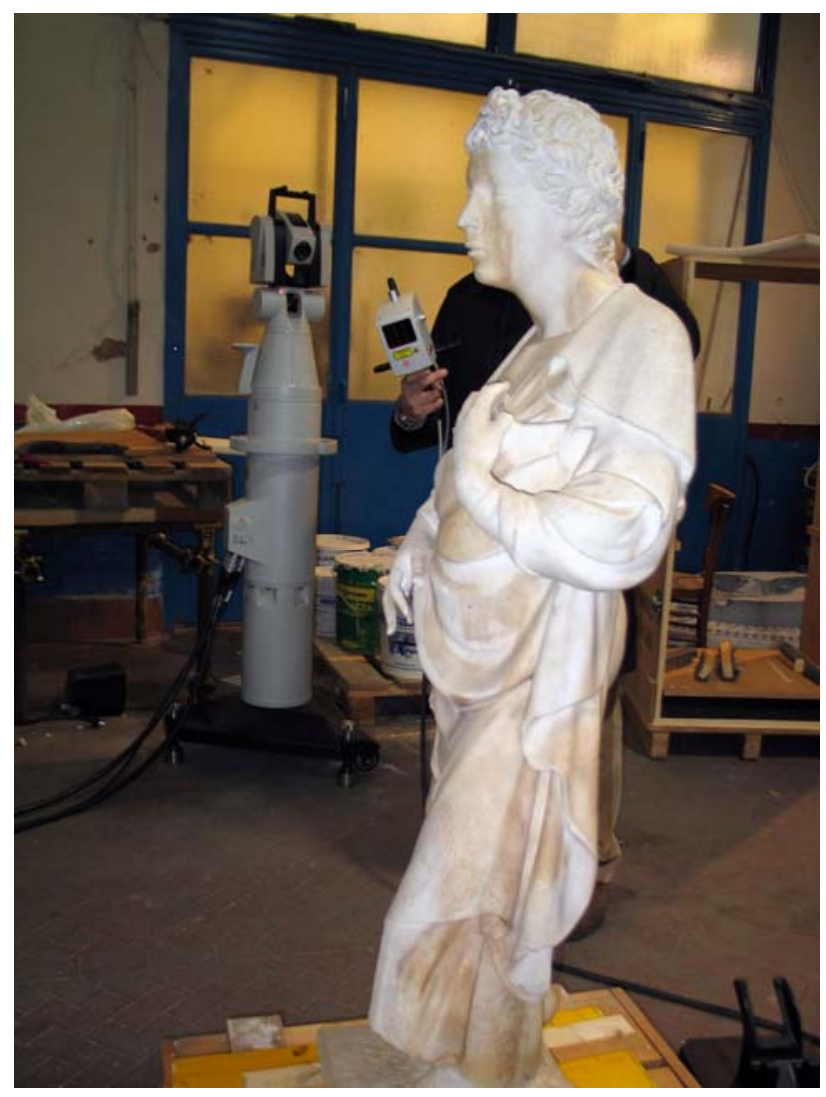

Figure 2. A statue surveyed by T-Scan and Laser Tracker system

\section{TERMINOLOGY ISSUES AND DEFINITIONS}

In industrial applications, the term Reverse Engineering is used to describe a process that involves measuring a real object and then reconstructing it as a $3 \mathrm{D}$ model. The analogous process in the Cultural Heritage field is generally called "survey". Terminology commonly used to define construction of 3D solid 
models may be vague or not precise, causing confusion between the general process and the specific technologies. "Rapid prototyping" is one of the most widespread; Stratasys proposes "Digital Direct Manufacturing" to distinguish processes that use additive fabrication technologies from all others, underlying the digital nature of the model from which processing begins.

According to American Society for Testing and Materials definition (ASTM F2792-10), “Additive manufacturing” is the "process of joining materials to make objects from 3D model data, usually layer upon layer". Synonyms are additive fabrication, additive processes, additive techniques, additive layer manufacturing, layer manufacturing, and freeform fabrication.

Additive manufacturing opposes to conventional prototyping or subtractive manufacturing, which includes techniques to "make objects by removing material from a bulk solid to leave a desired shape” (ASTM).

\section{FOCUSING ON CULTURAL HERITAGE APPLICATIONS}

All the terms above refer to the industrial world, such as the words "manufacturing" and "fabrication". In this sector the success of new production technologies is linked to the possibility of shortening the design and production cycle and therefore reducing costs. In fact, a "prototype" is a sample of a part or product fabricated before starting production to allow demonstration, evaluation or testing. Rapid prototyping techniques allow building functional prototypes, that are a sample part with performance or properties representative of the final product.

While prototyping systems are usually employed in the industrial processes where the prototype is previously planned in a CAD environment, in architecture and archaeology, the shape of interest is taken from a real-world object that does not have a pre-existing computer model. In fact, the main role of 3D solid models in architecture and archaeology is a sort of communication support, as a 3D visualization tool. Their mathematical description is often obtained as described in paragraph 2.

With the cross-migration of techniques to the Cultural Heritage documentation sometimes there are confused uses of terminology. "Prototype" is no more the first element of a subsequent production of a series. It is clear that the aim of a rapid prototyped project in this field is not to start mass production. Better terms to define this work could be "replica" or "solid model", depending on whether its scale is 1:1 or not.

In the early 1990s CAD had a lasting and far-reaching impact on the work of architects and archaeologists. A similar situation has occurred recently with the replacement of manual modelmaking with rapid prototyping techniques, now more and more frequent.

Models are used in Cultural Heritage field for several purposes: huge differences can be found between the models representing the only way of visualizing an architectural or design project before it was built and the models documenting the existence of an architectural element, an archaeological site or an antiquity. In both cases, models can be defined as "exhibitive": whether they are in full or reduced scale, their main function is representing the object they reproduce by overcoming the limitations of 2D images; applications can vary, as written in paragraph 8.

Following, only factors related to the processing that involves the superficial aspect of the solid model are analyzed. Some important aspects useful in other applications, e.g. mechanical behaviour of the used material or the method to realize the internal structure or possible supports of the model, are neglected. The most common dimensional accuracy requirements involved in architectural modelling are within the capabilities of additive manufacturing machines (over $0.2 \mathrm{~mm}$ ).

\section{HOW ADDITIVE MANUFACTURING WORKS}

Unlike traditional machining methods, additive manufacturing builds every part by adding material, layer by layer, rather than by subtracting it (see Paragraph 6). At present there are over 20 different recognized Rapid Prototyping technologies. The majority has been developed and optimized to produce objects with functional capability. We introduce here only the ones that can be used for models whose main aim is display ("exhibitive solid models").

\subsection{Stereolithography (SL)}

It was the first generation of machines for rapid prototyping (the first commercial machine dates back to 1987); it builds plastic parts or objects a layer at a time by tracing a laser beam on the surface of a vat of liquid photopolymer. After building, parts are removed from the machine and post-processing in a UV or thermal oven is used to cure any uncured resin. SL has a superior accuracy and definition when compared with other processes. SLA (Stereolithography apparatus) denotes the SL machines from 3D Systems Corporation.

\subsection{Laser Sintering (LS)}

It is based on bonding powders: one or more laser selectively fuse or melt, layer by layer, the particles at the surface. A fresh layer of powder is then added to the top and a new profile is traced by the laser bonding it to the layer below. The unfused powder acts as a supporting material which obviates the need for support removal during post-processing.

Actually, the word "sintering" is not correct, as the material is not sintered but partially or fully melted. The first machine was commercialized in 1992.

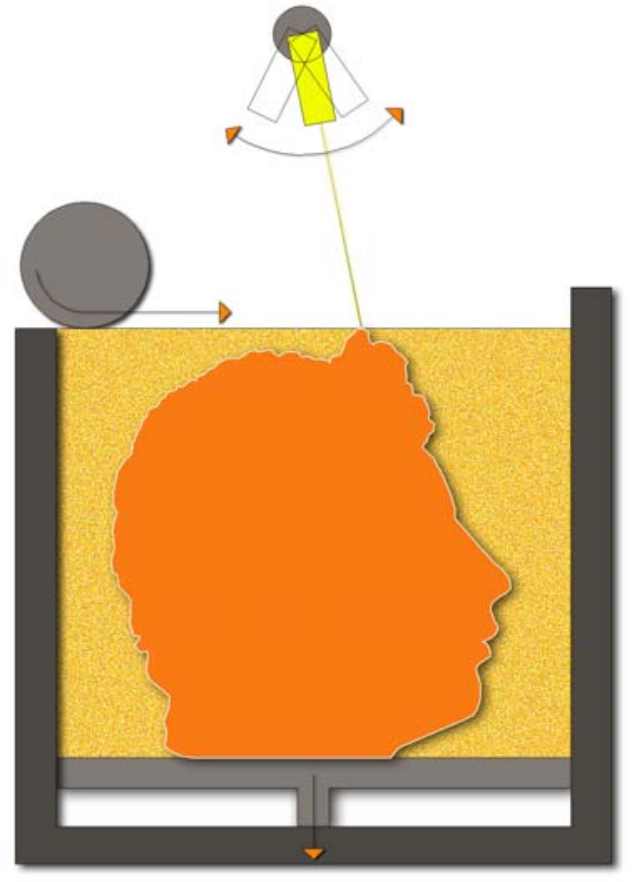

Figure 3. Schematic of the laser sintering process 


\subsection{Three dimensional printing}

A jetting which deposits a liquid adhesive compound onto the top layer of a bed of powder object material. 3D printing is often used synonymously with additive manufacturing, even though according to ASTM it should be reserved for this specific kind of process.

In 2001 ZCorp introduced the first commercial colour system: once the layer of powder is spread, the inkjet print heads print the cross-sectional area for bottom slice of the part onto the smooth layer of powder, binding the powder together: the coloured ink also provides the mechanical bond between the powder particles.

Resolution suitable for fairly good output is limited by layer thicknesses $(0.05-0.1 \mathrm{~mm})$ : while horizontal resolution is easily achieved, vertical resolution would require to reduce the layer thickness, slowing down the model building.

\subsection{Fused Deposition Modeling (FDM)}

It works by extrusion of thermoplastic materials, heated and deposited layer by layer. The term denotes machines built by Stratasys, Inc., which started commercializing it in 1991. Support removal can be manual or, when water soluble supports are employed, they may simply be dissolved.

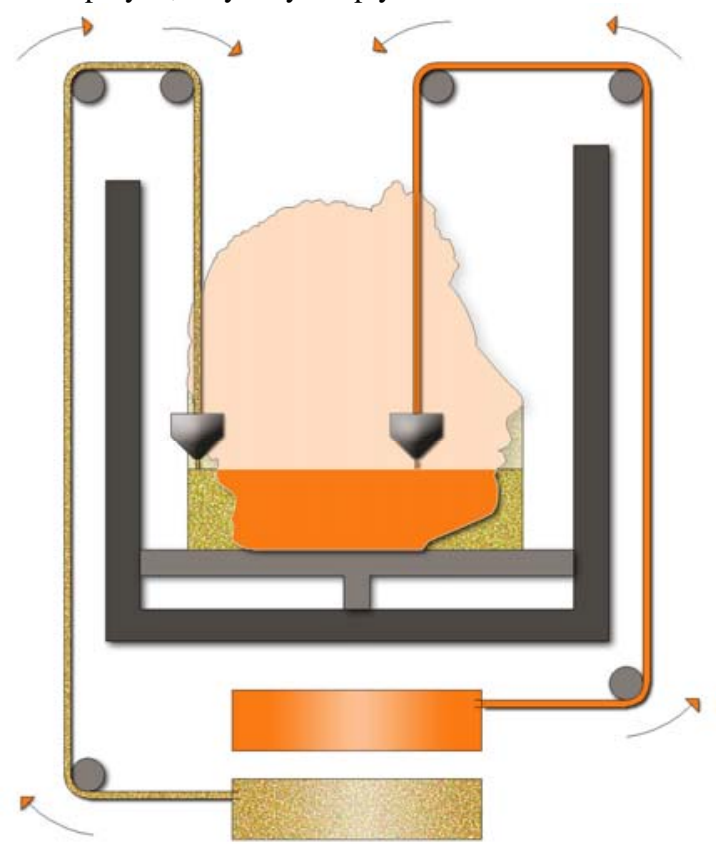

Figure 4. Schematic of the fused deposition modeling process

\subsection{Others manufacturing techniques useful for exhibitive} solid models

Laminated Object Manufacturing (LOM): a laser cutter or a knife cuts profiles of object cross sections from paper or plastic. This method is often applied to large models that require particularly robust properties. Surface finishing by hand is needed to remove layer steps.

Additive/subtractive Solid Freeform Fabrication (A/S SFF): it combines the advantages of layered manufacturing and material removal processes, such as CNC milling, so it can build parts with complex shapes without compromising precision requirements.

\subsection{Low cost and DIY projects}

In the industrial sector the reduction of time to market lead to remarkable cost reduction (that is to say gains). The resulting increase in market shares can justify demanding investments and the revision of a huge part of the production cycle.

If we replace the market value with the social value, the "industry" linked to Built Heritage will have huge potentialities in terms of potential users, improvement of the level of education and training, etc. which very rarely correspond to suitable economic resources. Maybe the offer of "low cost" machines and the availability of "Do It Yourself" systems could contribute to a wider spreading of additive manufacturing systems in this sector. Some examples are available in: http://reprap.org/wiki/Main_Page

http://www.evilmadscientist.com/article.php/candyfab http://3dprinting.co.nz/?page_id=5

\section{HOW CONVENTIONAL PROTOTYPING (CNC) WORKS}

CNC (Computer Numerical Control) machines make solid models by removing material from a stock shape of material. CNC machine can make different kinds of manufacturing: turning, trimming, drilling, planning, grinding, spark erosion, etc... An important element of a CNC machine is how many axes it has: more axes mean more complexity but also more complex shapes that can be worked. To make simple work, i.e. drilling holes, the motion control along three axes is needed: two of them in order to position the tool over the hole to be machined and the third to machine it. It is clear that working all around a full relief piece needs more complex movements.

The directions of motion can be linear (driven along a straight path) and rotary (driven along a circular path). All movements are related to a "zero point", useful in case of repositioning of the work in following steps to refinish it. The motion type, the axis to move, the amount of motion, and the feed rate are controlled by software. Machines with 5 axes have the highest flexibility: a rotating table can be added to have the 6th movement direction. The main advantage of 5 axis machining is the ability to work complex shapes in a single set-up. Additional benefit comes from allowing the use of shorter cutters that permit more accurate machining. CNC systems can process different materials: polystyrene, wood, stone, and so on.

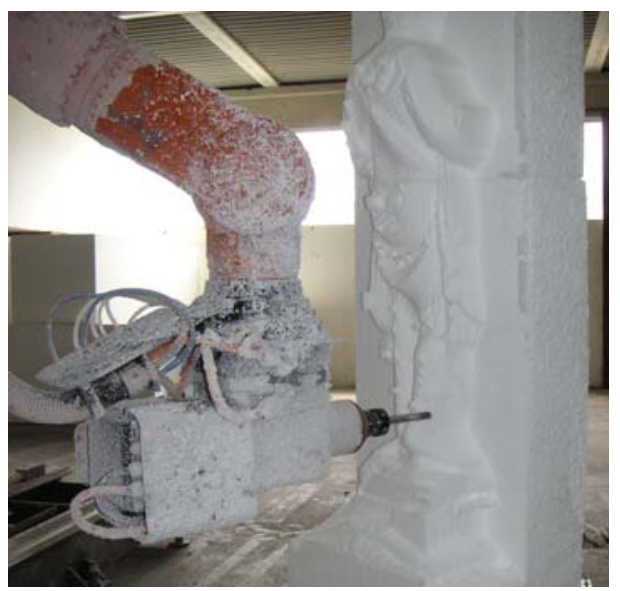

Figure 5. A CNC robotic milling machine working on the replica of the stature in Figure 2 


\section{WORK-FLOW}

\subsection{Numerical description of the object}

CAD model can be created as a solid model (by using primitive instancing or constructive solid geometry) or a surface model (by using B-rep). In order to create good files, all surfaces must be joined so that there are no gaps or overlaps. This stitching or sewing, is a manual and tedious process.

If it comes from a survey carried out with 3D scanning, the surface of the model is generally calculated by triangulating the data acquired.

Creating a hollow part is a good technique to cut down the weight of the prototype. This is important because volume is one of the main factors that play into the price of the prototype.

\subsection{Data preparation}

Data preparation is the manual or automatic control of the closing of all surfaces, which should create a "waterproof" model. If the size of the models under consideration exceeded the maximum dimensional capabilities of the machine, it should be split into several different parts, which will be produced separately.

\subsection{Surface tessellation}

The inner and outer surface of the numeric model is tesselled with polygons, generally triangular. If the initial model is made of NURBs surfaces, such as for example models of architectural elements or objects during the project stage, approximation with triangular facets will inevitably causes errors, which will be evaluated by using the distance between the centre of gravity of the triangle and the original surface (that is called chordal error). It could be necessary to diminish the size of the mesh; if their size is too big, facets will show on the solid model. Ideally, the triangle size should be close to the layer thickness used by the rapid prototyping system.

The tesselled model is stored in STL format (sometimes STL comes from Stereolitography, other times from "Solid To Layer"). The STL format stores the 3 coordinates of the vertex of every triangle and the direction cosine of the outward normal of the surface.

\subsection{Orientation and slicing}

The layer thickness should be chosen according to the necessary level of detail, and it can vary from some 0.1 to some $0.01 \mathrm{~mm}$. Special care must be take in the orientation of the various parts to ensure best quality and to minimize finishing time of the models: build orientation is important because solid models are usually weaker and less accurate in the vertical direction than in the $x-y$ plane; in addition, placing the shortest dimension in the vertical direction reduces the number of layers, thereby shortening build time.

\subsection{Making the solid model}

The technology chosen to build the solid model affects the build time and the operations necessary to finish the model, as shown in paragraph 5. Deposition of sliced layers leads to staircase effect that cannot be eliminated on a rapid prototyped part completely. Refinement of layers improves the surface finish of the part, but it increases the build time.

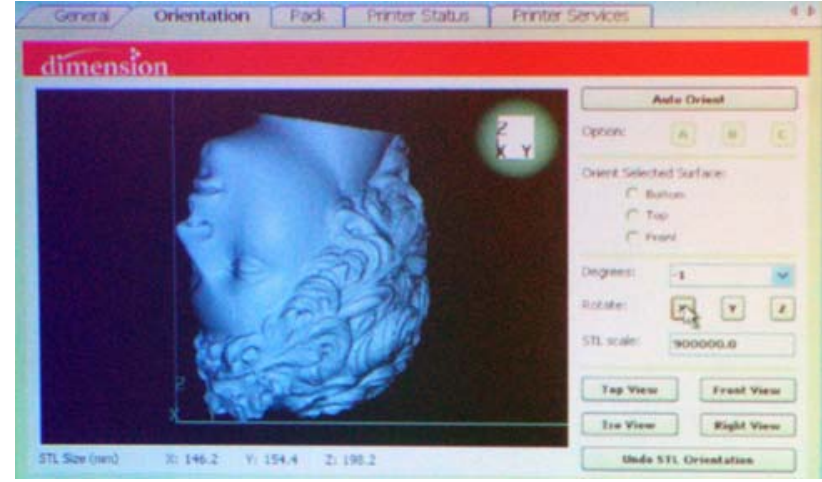

Figure 6. Orientation of the model

\subsection{Final operations}

The final steps are removing the part from the machine, detaching support materials, and performing any necessary cleaning or surface finishing. Polishing, sealing, or painting the parts can improve their appearance.

\section{EXAMPLES AND APPLICATIONS}

According to the purposes of the solid model to build, it is important to evaluate these aspects in advance:

- Working precision, according to the level of detail required;

- Surface aspect: colour, roughness, and so on;

- Mechanical strength, thermal strength, etc., if the model needs to have functional features;

- Possibility of applying finishing;

- Weight of the finished model.

Further paragraphs illustrate some of the 3D solid models built recently at the Geomatics and Communication Lab of the University of Florence.

\subsection{New project models}

Solid models often replace traditional maquettes built for demonstration and assessment of a proposed design project. In architecture schools the didactic function of building solid models has always been considered essential, as they are an effective tool to express and communicate even complex volumes. Students are more and more willing to represent their projects with $3 \mathrm{D}$ virtual models, which can be turned into solid models, of course.

In 2005 in Aarhus, Denmark, the Ethnographic Museum of Moesgård planned an extension of the exposition area through an international competition.

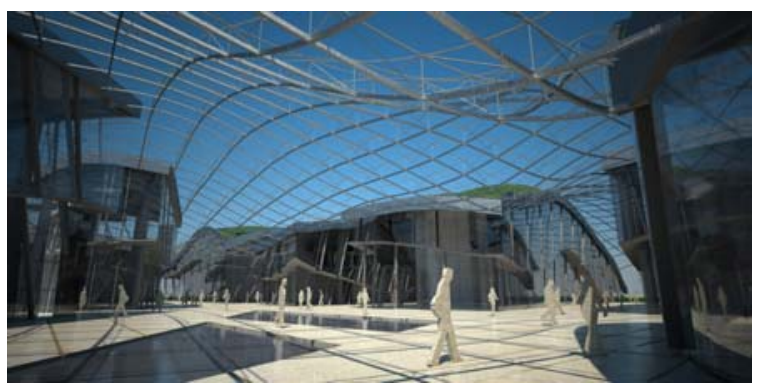

Figure 7. A rendered view of the designed exposition area 


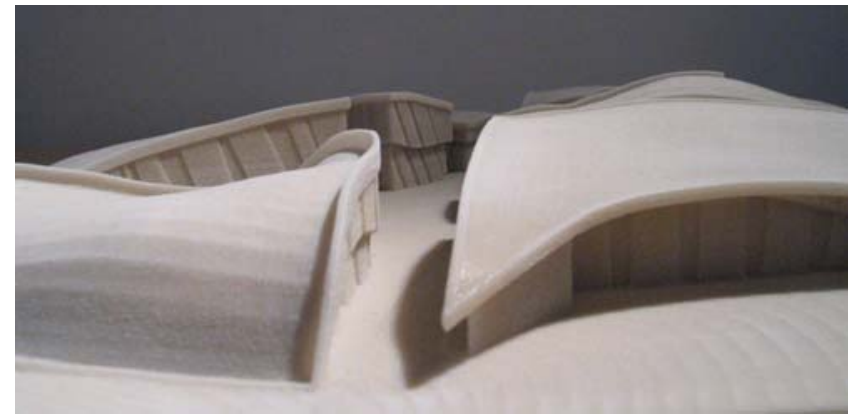

Figure 8. Solid model - 3D printed

This was a chance to experiment a new way of design: no more static drawings and then renderings, but a dynamic process of 2D, 3D, where parametric data inputs generate "virtual" models and "real" prototyped models, and all together became parts of the entire design`s process.

\subsection{Demonstration and reconstruction models}

The physical model of the archaeological remains of S. Maria del Lavello (Lecco, Italy) was rapid prototyped using 3D printing technique. At the end of the archaeological surveys, the excavation area was covered with a new suspended floor. The solid model was placed near the church and it currently represents the only visible evidence of the structures discovered underneath.

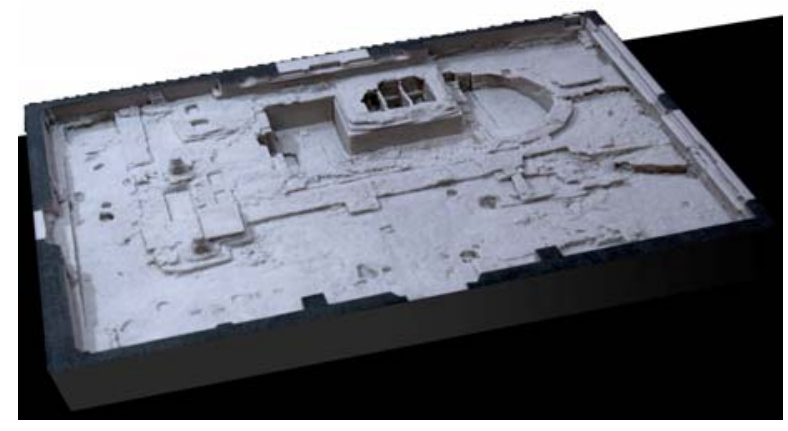

Figure 9. Solid model of Santa Maria del Lavello (Lecco, Italy) archaeological remains $-3 \mathrm{D}$ printed

The model of the Annunciation's Grotto in Nazareth was rapid prototyped using a laser sintering machine. After last restoration works pilgrims can't access to the grotto any more. In order to show the inner parts, the 3D model can be opened.

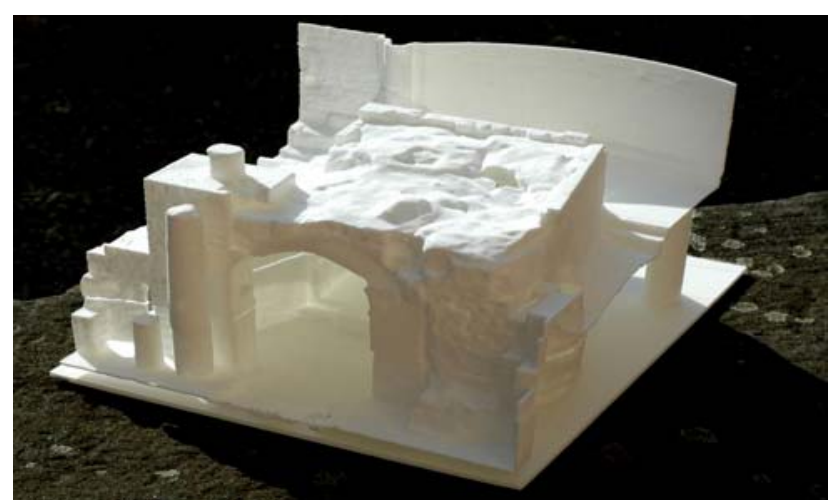

Figure 10. Solid model of the Grotto of the Annunciation (Nazareth, Palestine) - sinterized
At the end of the European project on Northen villages in Syria, a 1:20 scale was used for the models of the dwelling units of the village of Er Raheb. The model retains a high degree of detail, making it possible, for example, to distinguish the different types of wall texture or to recognize minute details.

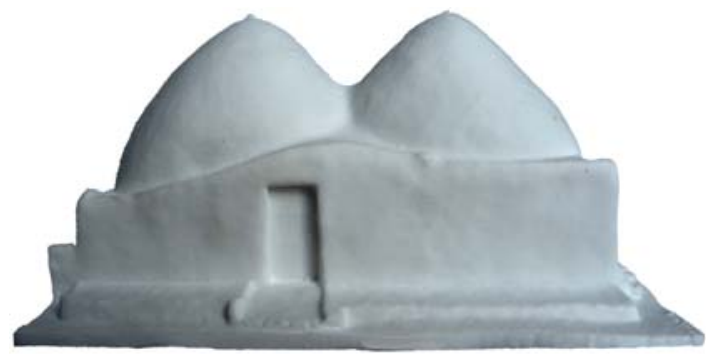

Figure 11. Solid model of dwelling units in the village of Er Raheb (Syria) - sinterized

\subsection{Replicas for replacing objects which must be transferred in a museum}

The poor state of preservation and the forms of degradation due to air pollution often suggest moving statues or architectural elements from their original position to more protect environments, such as exhibition rooms or museum warehouses. To have again the possibility of admiring these works in their original context, often copies are made. The images (Figures 2, 12 and 14) show the first results of a project aiming at evaluating potentialities and criticalities of prototyping systems in a "replica" of the statue of a Prophet originally located beside one of the entry to the Florence Cathedral. For this purpose, different technologies and materials were tested. A solid model of the whole statue, at 1:1 scale, was made in polystyrene by a CNC robotic milling machine. For this, a cylindrical cutter with $40 \mathrm{~mm}$ diameter for the roughing, a spherical cutter with $20 \mathrm{~mm}$ diameter for the finishing and a spherical cutter with $10 \mathrm{~mm}$ diameter to retouch the surface and to produce finish geometry have been used. Finish pass was of $1 \mathrm{~mm}$. (See Fig. 12)

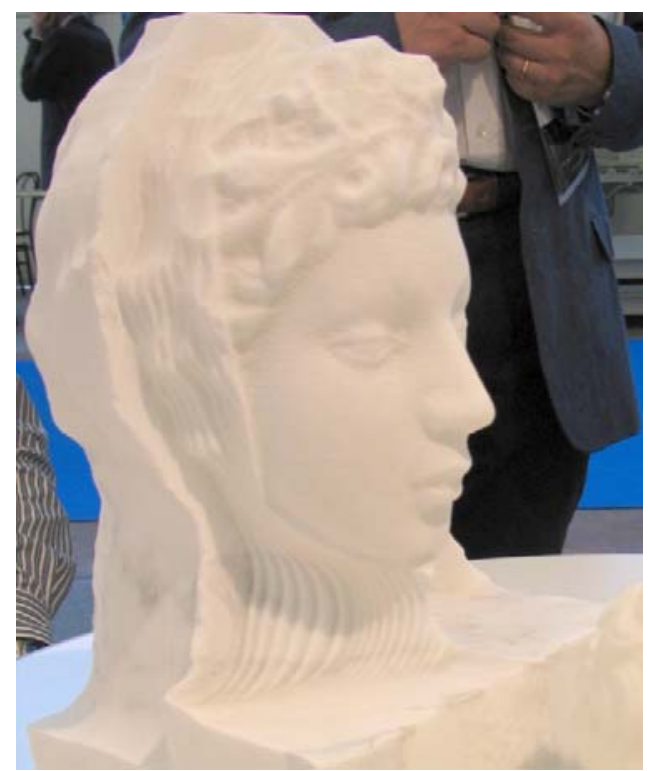

Figure 12: The marble replica of a statue's head at an intermediate working phase: subsequent step of machining are visible; the level of detail showed on the face is the last finishing obtained 
A solid model of the Prophet's head, at 1:1 scale, was made in marble by another robotic milling machine (Robostone 3000). The three subsequent steps of machining are visible on the same model: the roughing on the back (made by a cutter of $50 \mathrm{~mm}$ diameter), the semi-finishing of the face (with the same cutter) and the finishing (with a " $\mathrm{V}$ " widia point of $5 \mathrm{~mm}$, with passing of $0.9 \mathrm{~mm}$ ). The working direction for the finishing pass was at right angle to the working direction for the roughing pass. In both cases CNC machines have used a 3 axis tool path; the front finishing of the marble model has been made at 5 axes.

\section{4 “Tactile” models}

Now only a few museums are entirely dedicated to tactile models (in Ancona the Omero Museum, in Madrid the Museo Tiflológico, in Varese the Salvini Museum), that is to say full or reduced scale models of architectural elements, statues, archaeological findings, and so on. These models can be touched and explored by blind and partially sighted people that can perceive and understand objects; in fact, tactile observation is the main means of knowledge for blind people. The model exhibited are generally made with traditional techniques (wood or metal for the architectural ones, wood, bronze, fake marble and resins for statues) or by using CNC systems to build single parts.

At the end of the project, in collaboration with the Municipality of Perugia, we built a solid model of the heart of the old city centre, and a bigger scale model of the Palazzo dei Priori, which can be detached to show the inner rooms.

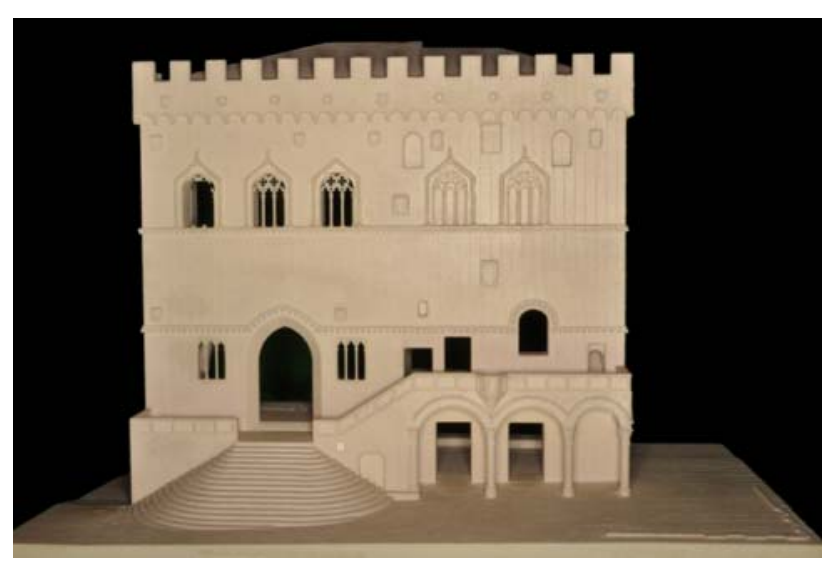

Figure 13. Solid model of the Palazzo dei Priori (Perugia, Italy) - 3D printed

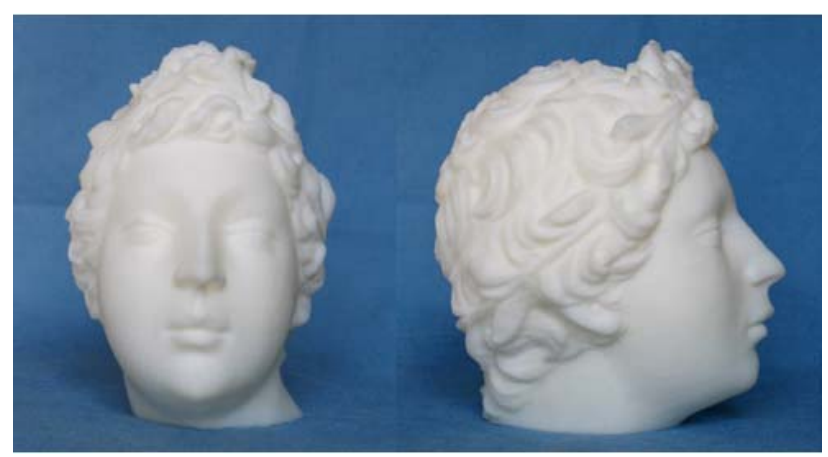

Figure 14. Real scale model of the head's statue shown in Fig. 2 - Fuse deposition model

\section{CONCLUSIONS}

The technologies available to build solid models are manifold and their use is already well-consolidated in the industrial sector, where they can speed up the production process through prototypes or tools; moreover, they are suitable to produce small series. Applications in communications of cultural heritage are diverse. In particular, we analyzed those considering solid models as a possible way of representing the data surveyed with geomatics techniques, in particular through scanning system, showing the results of some recent projects.

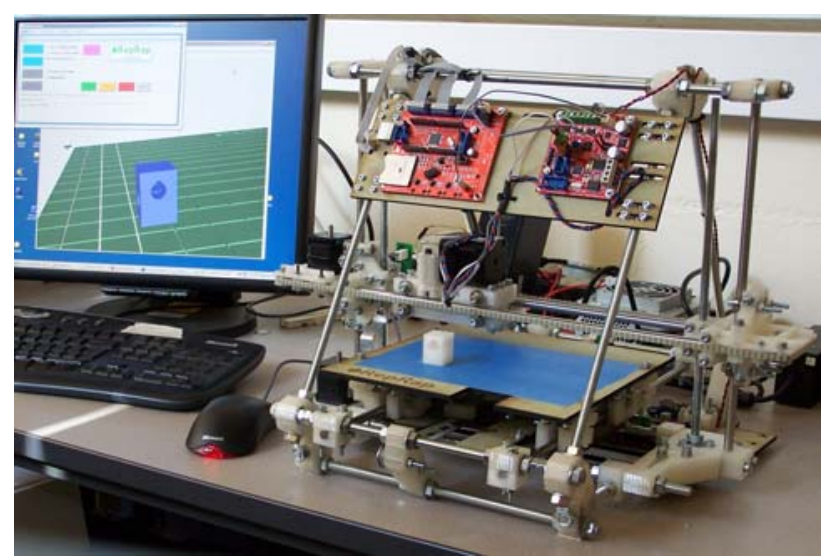

Figure 15. Mendel FDM system (RepRap project)

\section{REFERENCES}

Brajlih, T., Valentan, B., Balic, J., Drstvensek, I., 2011. Speed and accuracy evaluation of additive manufacturing machines, Rapid Prototyping Journal, Volume 17, n. 1, ISSN 1355-2546, pp. $64-75$.

(http://www.deepdyve.com/lp/emerald-publishing/speed-andaccuracy-evaluation-of-additive-manufacturing-machinesmlgorTJlsY)

Böhler,W., Marbs, A. 2002. 3D Scanning Instruments, Proceedings of CIPA WG6 Scanning for Cultural Heritage Recording, September 1-2, Corfu, Greece.

Bonora, V., Cruciani Fabozzi, G., Tucci, G., 2008. The use of 3D Scanning and Rapid Prototyping for the Documentation, Conservation and Communication of Archaeological Remains: a Recent Experience in the Sanctuary of S. M. del Lavello (Lecco, Italy) DMACH 2008 Conference "Digital Media and its Applications in Cultural Heritage", Petra University, Amman, Jordan, 3-6 November, ISBN 978-9957-8602-5-7, pp. 12-23.

Chua, C., Hong, K., Ho, S., 1999. Rapid tooling technology. Part 1. A comparative study, The International Journal of Advanced Manufacturing Technology, Springer London, ISSN 0268-3768

Chua, C.K., Leong, K.F., Lim, C.S., 2010. Rapid Prototyping : Principles and Applications, Word Scientific Publishing Co., ISBN 981-238-117-1.

Columbano, A. Dring, M., 2010. The pedagogy of using a RP architectural model, Virtual and Physical Prototyping, Volume 5, Issue 4, ISSN 1745-2767, pp. 195 - 200 
Dimitrov, D., Schreve, K., de Beer, N., 2006. Advances in three dimensional printing - state of the art and future perspectives, Rapid Prototyping Journal , Volume 12, n. 3, ISSN 1355-2546

Dolenc, A., Makela, I., 1994, Slicing Procedures for Layered Manufacturing Techniques, Computer-Aided Design, 26 (2), pp. 119-26.

Fantini, M., De Crescenzio, F., Persiani, F., Benazzi, S., Gruppioni, G., 2008. 3D restitution, restoration and prototyping of a medieval damaged skull, Rapid Prototyping Journal , Volume: 14, n. 5, ISSN 1355-2546.

(http://www.emeraldinsight.com/journals.htm?issn=13552546 \& volume $=14 \&$ issue $=5 \&$ articleid $=1747220$ \&show $=$ pdf)

Giannatsis, J. Dedoussis, V., Karalekas, D., 2002. Architectural scale modelling using stereolithography, Rapid Prototyping Journal , Volume 8, n. 3, ISSN 1355-2546

Gibson I., Ming, L.W., 2001. Colour RP, Rapid Prototyping Journal, Volume 7, n. 4, pp. 212-216

Grenda, E., 2010. Printing the Future, Castle Island (e-book)

Hopkinson, N., Hague, R.J.M., Dickens, P.M., 2006. Rapid Manufacturing: An Industrial Revolution for the Digital Age

John Wiley \& Sons, ISBN 0-470-01613-2.

Ippolito, R., luliano, L., Gatto, A., 1995. Benchmarking of rapid prototyping techniques in terms of dimensional accuracy and surface finish, Annals of the CIRP, 4411, pp. 157-160.

Kvan, T., Gibson, I. and Ming L.W. (2000), Rapid prototyping for architectural models, in Balkema, A.A., Goncalves, R., Steiger-Garcao, A. and Scherer, R. (Editors), Product and Process Modelling in Building Construction, ECPPM 2000, pp. 351-62.

Larsen, R., Barth, E., Kolb, A. (editors), 2010. Computer Vision and Image Understanding, Special issue on Time-of-Flight Camera Based Computer Vision, Volume 114, n. 12, Elsevier, ISSN 1077-3142

Levy, G.N., Schindel, R., Kruth, J.P., Rapid Manufacturing and Rpid Tooling with Layer manufacturing (LM) Technologies : State of the art and Future Prospectives, CIRP Annals Manufacturing Technology, Volume 52, Issue 2, 2003, Pages 589-609, ISSN 0007-8506, DOI: 10.1016/S00078506(07)60206-6.

(http://www.sciencedirect.com/science/article/B8CXH-

4P2B8WC-7/2/c2ec2f68b8c23b3040abc7615ef00fb9)

McDonald, J.A., Ryall, C.J., Wimpenny (Editors), D.I., 2001. Rapid Prototyping Casebook, Professional Engineering Publishing, ISBN 1860580769.

Pham, D.T., Dimov, S,S., 2001. Rapid Manufacturing : the Technologies and Applications of Rapid Prototyping and Rapid Tooling, Springer, London.

Tucci, G., Bonora, V., 2007. Application of high resolution scanning system for virtual moulds and replicas of sculptural work, International Archives of Photogrammetry and Remote Sensing, Vol. XXI-2007, ISSN 0256-1840 pp. 721-726.
Wohlers, T., 2010. Wohlers Report 2010, ISBN 0-9754429-6-1

References from websites (accessed January 2011)

http://www.3dsystems.com/

http://www.artec3d.com/3d_scanners/artec-mh

http://www.cc.utah.edu/ asn8200/rapid.html

http://www.creaform3d.com/en/handyscan3d

http://www.steinbichler.de/en/main/_t-scan_3_home_.htm

http://www.stratasys.com/

Direct Digital Manufacturing part one: what is direct digital manufacturing?,

http://www.stratasys.com/ /media/Main/Files/White\%20Papers /Stratasys_WP-Direct_Digital_Manufacturing-Part1-

FORTUS.ashx

ASTM F2792-10 Standard Terminology for Additive Manufacturing Technologies, http://www.astm.org

Museo Tiflológico in Madrid, http://www.once.es/home.cfm?id=271\&nivel=4\&orden=6

Museo Omero in Ancona, http://www.museoomero.it/ 